\title{
13
}

\section{Academic Air Travel Cultures: A Framework for Reducing Academic Flying}

Sherry H. Y. Tseng, James Higham, and Craig Lee

\section{Introduction}

As primary producers of knowledge, academics are required to create and disseminate research (Greenbank, 2006; Nursey-Bray et al., 2019). The advent of internationalisation has placed great emphasis on the importance of travel as it pertains to the success of an academic career and the international standing of an institution (Knight, 2011; Nursey-Bray et al., 2019). However, academics who are highly aeromobile-particularly researchers working in the field of climate change-are now facing allegations of hypocrisy which may compromise the efficacy of their (climate) research (Klöwer et al., 2020). While there is a building corpus of research that addresses academic flying practices, the novelty of this chapter arises from the application of the energy cultures framework (Stephenson et al., 2010) to the study of academic air travel. The energy

\footnotetext{
S. H. Y. Tseng $(\bowtie) \bullet J$. Higham $\bullet$ C. Lee

University of Otago, Dunedin, New Zealand e-mail: sherry.tseng@postgrad.otago.ac.nz; james.higham@otago.ac.nz; craig.lee@otago.ac.nz 
cultures framework comprises three key elements-cognitive norms, material culture and practices.

In this chapter, the issues of high carbon emissions and entrenched academic flying behaviours will be addressed first. The energy cultures framework is then discussed to consider how social and cultural factors, such as norms, social inequalities and social networks, interact with motivations and moderators to shape and influence flying behaviours. Next, consideration is given to the significant and immediate changes in academic practices that have been brought about by COVID-19. The practices of virtual conferences will be taken as an example to reconsider the necessity of academic air travel as conference attendance accounts for the highest proportion of academic flying (Wynes \& Donner, 2018). This will afford a timely opportunity to rethink the necessity of academic air travel based on the reformulated COVID-19 academic working environment. A modified energy cultures framework is then proposed and applied to model the interactions between social and cultural factors, on the one hand, and the motivations and moderators, on the other-in order to provide a pathway to reducing flying activity. The energy cultures framework is adopted to provide a structure within which to consider individual and institutional pathways to achieve significant reductions in academic flying. By exploring the interplay of cognitive norms, practices and material culture, the gap between academic theory and institutional realities and practices can be systematically explored and fully elaborated. The chapter concludes with reflections on the energy cultures framework and prioritises future research directions. In doing so, academics may be encouraged to engage in critical self-reflection of the cognitive dissonance between personal intentions to reduce air miles and behaviours to the contrary.

\section{Why Do Academics Fly?}

Before the enormous disruption caused by COVID-19, academics engaged in largely unquestioned air travel practices that were driven by institutional norms. At the institutional level, internationalisation is firmly embedded in mission statements, policies and strategies not only 
in organisations, companies and universities, but also in national policy (Hopkins et al., 2016). 'Internationalization' is a core value that is common to all high-ranking academic institutions (Rumbley et al., 2012; de Wit, 2018). In a globally competitive environment, air travel has become established as an enabler and marker of a successful academic workforce (Glover et al., 2019).

As primary producers and disseminators of knowledge, academics travel frequently to strengthen their abilities and maintain their visibility under the internationalisation imperative. International collaborations, international journal publications and competitive research grants are widely regarded as key measures of academic success and markers of global intellectual capital (Glover et al., 2019). To demonstrate international standing, institutions measure the number of publications in international journals, the number of international students/staff and their collaborative projects.

Most universities are aspirational in terms of their standing on global university rankings. In collecting and considering data for the Times Higher Education World University Rankings, international outlook accounts for 7.5 per cent of the ranking score. Here, the Times Higher Education World University Rankings calculates the proportion of a university's total research journal publications that have at least one international co-author and reward higher volumes for the indicator: International Collaboration (Times Higher Education, 2020). This kind of pressure from the education system as a whole forces academics to travel more in order to meet internationalisation expectations. For example, Glover et al. (2019) found that 48 per cent of academics think their employer encourages air travel. This indicates that academic flying practices have become entrenched among scholars who, beyond the immediate interests of career success, may have continued to function in accordance with the internationalisation imperatives of their institutions (Nursey-Bray et al., 2019).

At the individual level, it is generally accepted that air travel and faceto-face meetings are absolutely irreplaceable elements of a successful academic career (Glover et al., 2019; Nursey-Bray et al., 2019). By travelling and meeting international peers, academics not only disseminate and promote their own research (Nursey-Bray et al., 2019), but also build 
their social networks (Higham et al., 2019; Lassen et al., 2006; NurseyBray et al., 2019). From a personal perspective, building social networks by presenting, meeting, networking and socialising at conferences is critical to climbing the academic career ladder. Networking is a very common justification for air travel, extending to informal social networking and the forging of relationships characterised by a strong need for physical proximity and co-presence (Lassen et al., 2006). Despite our globalised world, face-to-face trust and implicit knowledge between peers still dominate over intermittent digital communication (English-Lueck et al., 2002; Growe, 2019). A face-to-face meeting is a strong facilitator for building both recognition and interpersonal trust, such as meeting the editors of high-impact journals (Higham et al., 2019). Urry (2012) considers physical travel to be required to maintain academic productivity and ensure job satisfaction.

\section{Issues Concerning Academic Flying}

Worldwide, transportation is responsible for 24 per cent of annual global emissions of carbon dioxide $\left(\mathrm{CO}_{2}\right)$ (International Energy Agency, 2020). In 2019, air transport produced 915 million tonnes of $\mathrm{CO}_{2}$ or approximately 2 per cent of anthropogenic $\mathrm{CO}_{2}$ emission (Air Transport Action Group, 2020). Prior to 2019, emissions from global air transport were known to be increasing at an accelerating and unsustainable rate (Overton, 2019). If air transportation technology can be improved to 100 per cent biofuel, aviation will have consumed 12 per cent of the global carbon budget for $1.5^{\circ} \mathrm{C}$ by 2050 (Carbon Brief, 2016; International Civil Aviation Organization, 2017). If the industry fails to reach this target and assuming the international flights grows 5 per cent per year, its share of the budget could rise to as much as 27 per cent (Carbon Brief, 2016; International Civil Aviation Organization, 2017).

Because of intensifying concern that the world is failing to deal with accelerated global warming, there has been growing disquiet over the carbon footprint of academic travel (Eriksson et al., 2020; Grant, 2018). Since they are aware that the environmental impact of academic flying is an integral ethical and moral consideration in academic work, many 
academics across different disciplines have dedicated themselves to developing methods to reduce aviation-related carbon emissions from technological, social, economic and cultural perspectives (Grant, 2018). For example, the use of biofuel in aviation is regarded as a viable technological strategy to mitigate climate change (Moore et al., 2017). Moreover, Carbon Offsetting and Reduction Scheme for International Aviation (CORSIA) is an economical method to achieve the global aspirational goal (International Civil Aviation Organization, 2020). Academics serve as critic and conscience of society (Education Act, 1989), and they have been vocal in urging preventative measures against climate change to society. But, they are encouraged to travel to build their collaborative networks, to produce high-impact research and to maintain visibility, all of which is encouraged by institutions that seek to internationalise (Storme et al., 2013; Wynes et al., 2019).

Work-related travel, such as attending conference and fieldwork, is a major carbon-emitting activity for climate change researchers (Whitmarsh et al., 2020). Before the COVID-19 pandemic, many academics accumulated vast air miles due to the frequent long-haul flights they took. Due to the highly aeromobile activity, it becomes an important task for climate change researchers to curb their own aviation emissions to align their practices with their assertions in relation to emissions reduction (Whitmarsh et al., 2020). Klöwer et al. (2020) point out that at the world's largest earth and space science conference-the Fall Meeting of the American Geophysical Union (AGU) - 28,000 delegates travelled 285 million kilometres return and emitted about 80,000 tonnes of $\mathrm{CO}_{2}$.

There is an active debate as to whether extensive academic travel is justified by the positive contribution that academic research and teaching provides to society (Buchs, 2019). Wynes and Donner (2018) used the University of British Columbia (UBC) as an example and analysed UBC's business-related air travel emissions. UBC's annual business-related air travel emissions were found to be 63-73 per cent of the total emissions of the entire institution. Emissions associated with conferences accounted for 55 per cent of the listed main purpose of their business travel.

The responses to climate change from every university are different; some universities do not recognise air travel as an issue, some recognise the problem but have no sustainability policy, while others try to reduce 
their air travel via alternatives such as virtual meetings or different transportation modes (Glover et al., 2017). While many universities emphasise sustainability, there seems to be little integration of their sustainability rhetoric within wider policies. For example, academics are usually asked to consider aspects of their travel such as transportation mode, duration of travel and necessity of travel from a financial rather than an environmental perspective (Hopkins et al., 2016). Institutions have implemented policies to achieve both the mutually exclusive goals of internationalisation and sustainability, highlighting a disconnect within and between policies at institutions (Hopkins et al., 2016). Therefore, institutions cannot claim to be working towards meeting sustainability targets without tackling the issue of their academics' air travel emissions.

In addition to the high environmental cost, some researchers argue against the necessity of flying for face-to-face meetings and conferences based on funding and professional success issues. The inclusiveness of current meetings and conferences is sometimes questioned because of the expensive cost for transportation and accommodation and the high cost of attendance fees for conferences. These are key reasons which keep emerging researchers from labs, low- to middle-income countries and junior principal investigators away from other researchers (Sarabipour et al., 2020). Furthermore, Wynes et al. (2019) found that in-person conference attendance is not linked to career progression, and air travel does little to boost academic productivity or encourage collaborations. In addition, when measured against per annum salary increase, frequent air travel does not coincide with career success. Also, for some academics, it is very difficult to find a balance between personal achievement and family life. Academics travel to attain a successful academic career, but in doing so, they may sacrifice family time (Higham et al., 2019). Travelling may be a source of stress and frustration for academics and their family, which skews the work and life balance of academics. These findings provide academics with a chance to rethink the necessity of their academic flying intentions.

Addressing the high emissions of academic air travel is a complex field to contemplate. It is necessary to consider how social and cultural factors, such as norms, social inequalities and social networks, interact with motivations and moderators to shape and influence flying behaviours. Within a complex system such as transportation, single-discipline solutions are 
typically ineffectual. Conceptual models are necessary not only to identify key interactions and opportunities for change but also to bridge different perspectives across academic disciplines (Stephenson et al., 2015b). The energy cultures framework (Stephenson et al., 2010) is discussed in the next and subsequent sections as a potential pathway to reduce academic flying not only through the decisions and actions of individuals but also by identifying and addressing structural issues.

\section{The Energy Cultures Framework}

The energy cultures framework was originally developed in the context of renewable energy use to understand the factors that influence energy consumption and to identify opportunities for behavioural change (Stephenson et al., 2010). It has been applied to evaluate behavioural changes relating to energy saving (Sweeney et al., 2013), energy transitions (Sarrica et al., 2016), personal mobilities (Hopkins \& Stephenson, 2014), the reduction of automobility (Hopkins \& Stephenson, 2016) and conceptualising transport transitions (Stephenson et al., 2015b). The energy cultures framework is a useful tool as it provides an interdisciplinary language which is useful and easy for researchers from different disciplinary perspectives to understand how the different elements interact within the socio-technicalcultural sphere (McKague et al., 2016; Stephenson et al., 2010).

The energy cultures framework is useful in complex systems to understand the different ways elements interact within the socio-technicalcultural sphere. Because of this simplicity, this framework is general enough to be applied to studies in different disciplines (Stephenson et al., 2015a). Moreover, the energy cultures framework can be applied to different scales, such as the individual or household through to the institutional or national scale. It can also be used in different areas/scales such as urban, regional or national. The energy cultures framework is easily adapted and applied to a wide range of study contexts. It accommodates the fact that the culture of one individual or one area/scale may be very different from another. For example, at the individual level, the academic flying culture of an early-stage academic may be very different from the materials, norms and practices of a mid-career or senior academic. The 
simplicity of the energy cultures framework allows it to be shared amongst researchers from different disciplines in order to widen the pool of experience and perceptions accessible from each of the different disciplines (Stephenson et al., 2015a).

The energy cultures framework (see Fig. 13.1) was developed based on a recognition of the complex interactions amongst cognitive norms, material culture and practices. The behaviours that arise from the interplay among these three elements of the framework are only somewhat shaped by the individual (Stephenson et al., 2015a). In addition, the behavioural patterns arising from these elements of the framework can be difficult to deviate from, due to the elements interacting with each other in ways that are mutually reinforcing. The example of new multimobilities culture (the element of the push to use multiple modes of transportation) will be taken to explain how the elements from Hopkins and Stephenson (2016) influence the reduction of automobility through their application of the cultures framework. Hopkins and Stephenson (2016) use the energy cultures framework as a foundation to explore how cognitive norms, material culture, practices and external influences reduce participation in automobility culture amongst young adults.

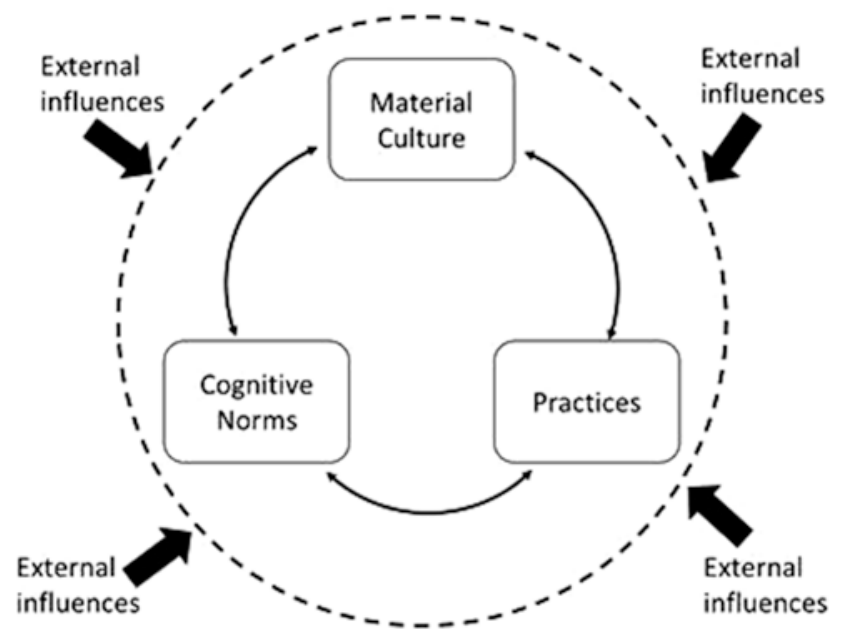

Fig. 13.1 The cultures framework. (Stephenson et al., 2010, 2015b) 
Cognitive norms reflect the attitudes, values, beliefs and understandings of specific behaviours. In the framework, norms are an individual's expectations and aspirations about their practices and material culture (Hopkins \& Stephenson, 2016; Stephenson et al., 2010, 2015a; Sweeney et al., 2013). It strongly influences an individual's choice of technologies and the practices that they undertake (Stephenson et al., 2010). In the example of the multi-mobilities culture to reduce automobility, awareness of the carbon intensities of transport modes, an interest in increasing physical activity and aspirations to dematerialise are included in cognitive norms (Hopkins \& Stephenson, 2016).

Material culture refers to relevant technologies and physical infrastructures that play a role in how aeromobility can be reduced, including virtual communication products, transport infrastructure and other available technologies (Hopkins \& Stephenson, 2016; Stephenson et al., 2010, 2015; Sweeney et al., 2013). Material culture has a strong effect on cognitive norms and on the range of an individual's potential energy practices (Stephenson et al., 2010). Taking reducing automobility as an example, the different types of transportation mode and the facilities used for public transportation, such as public transport timetables, bus passes, rain jackets and walking shoes, are regarded as crucial aspects of material culture that are required to increase the usage of public transportation and reduce automobility (Hopkins \& Stephenson, 2016).

Practices are everyday activities, including regular and irregular actions (Hopkins \& Stephenson, 2016; Stephenson et al., 2010, 2015a; Sweeney et al., 2013). They determine how technologies are used and also partly shape people's beliefs, understandings and reactions (Stephenson et al., 2010). In the example of building a multi-mobilities culture, practices of this element would be characterised by the use of a range of transportation modes, rather than a single mode of transportation, to reduce automobility, urbanised lifestyle, multi-modality and shared mobility are the practices which are included in the model (Hopkins \& Stephenson, 2016).

These three elements not only influence each other but are also influenced by external factors. External influences are factors that individuals have little or no control over but have the potential to shape individual's norms, practices or material culture (Hopkins \& Stephenson, 2016; Stephenson et al., 2010). In the example of building a multi-mobilities 
culture to reduce automobility, external influences such as changes to driving test rules and regulations, health concerns and public transportation infrastructures are the factors which can drive change in one or more of the internal elements away from car dependency and may contribute to the destabilisation of automobility (Hopkins \& Stephenson, 2016). These factors enable and perform alternative mobilities (Hopkins \& Stephenson, 2016). By adding the impacts caused by external influences, the energy cultures framework is regarded as a strong model to form the basis of energy behaviour cultural studies (Klaniecki et al., 2020; Stephenson et al., 2011; Walton et al., 2020).

In the original energy cultures framework, Stephenson et al. (2010) focused on the wide array of different factors influencing energy behaviours. In the years since, the framework has evolved and expanded to reflect the behaviours of all participants in energy systems. This refinement not only explicates the interactions between norms, practices and material culture but also key external influences (Stephenson et al., 2015b). Despite this, some researchers criticise the oversimplicity of the model and point out the lack of key elements in behavioural change such as motivation, barriers or distinct circumstances (McKague et al., 2016; Sweeney et al., 2013). McKague et al. (2016) and Sweeney et al. (2013) described the energy cultures framework as providing elements which act in isolation.

In response, Sweeney et al. (2013) extended the framework by framing a person at the centre of all interactions and regarding the individual as driven by motivations towards a behavioural goal-the practice-based energy cultures framework (see Fig. 13.2). In the practice-based energy cultures framework, the material culture, cognitive norms and practices were at the outer ring and categorised as the communal/cultural level. Sweeney et al. (2013) also considered the motivation, support, barriers and constraints as critical factors when developing behaviours since they were recognised as core determinants of energy-saving behaviours. In this model, Sweeney et al. (2013) emphasised that a change in one component of the framework will lead to changes across all of the components in the framework until a balance between components is achieved.

The support, barriers, constraints and external influences broadly influence individual energy behaviour on both social and cultural aspects. To develop a comprehensive framework of academic flying in this 


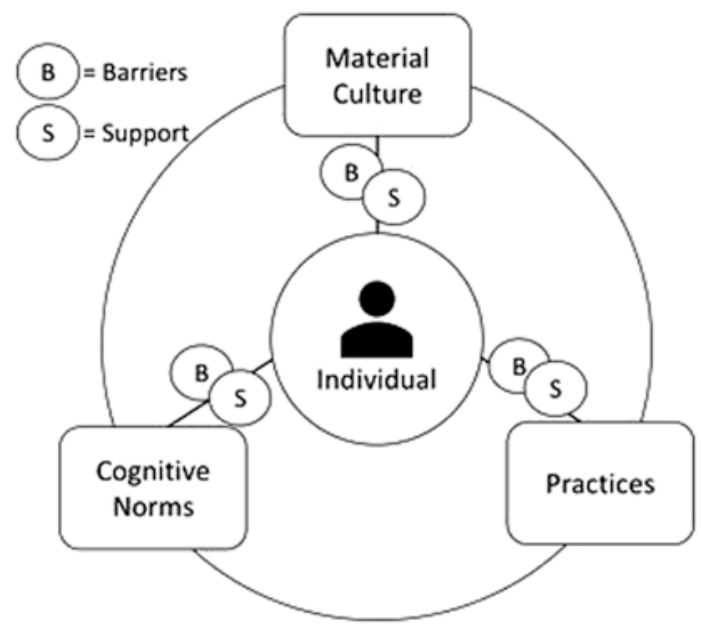

Fig. 13.2 The practice-based energy cultures framework. (Sweeney et al., 2013)

chapter, we regard these factors as moderators, in that they can change the strength or nature of the relationships among the core elements and motivations (Hair Jr et al., 2016). In order to address limitations and develop a comprehensive model, this chapter will integrate the original energy cultures framework (Stephenson et al., 2010) and the practicebased energy cultures framework (Sweeney et al., 2013). The proposed framework not only focuses on the interactions among material cultures, cognitive norms and practices but will also emphasise the impact of moderators (see Fig. 13.3). In doing so, the impact of moderators and the relationships between moderators and cognitive norms, material culture and energy practices will be clear and easily evaluated by future research.

\section{The Impact of COVID-19: Rethinking Academic Air Travel}

The outbreak of COVID-19 at the end of 2019 induced panic throughout the world (Nicomedes \& Avila, 2020) and extensive social and economic lockdown. A study shows that the COVID-19 outbreak significantly affected the mental health of the Chinese public; this 


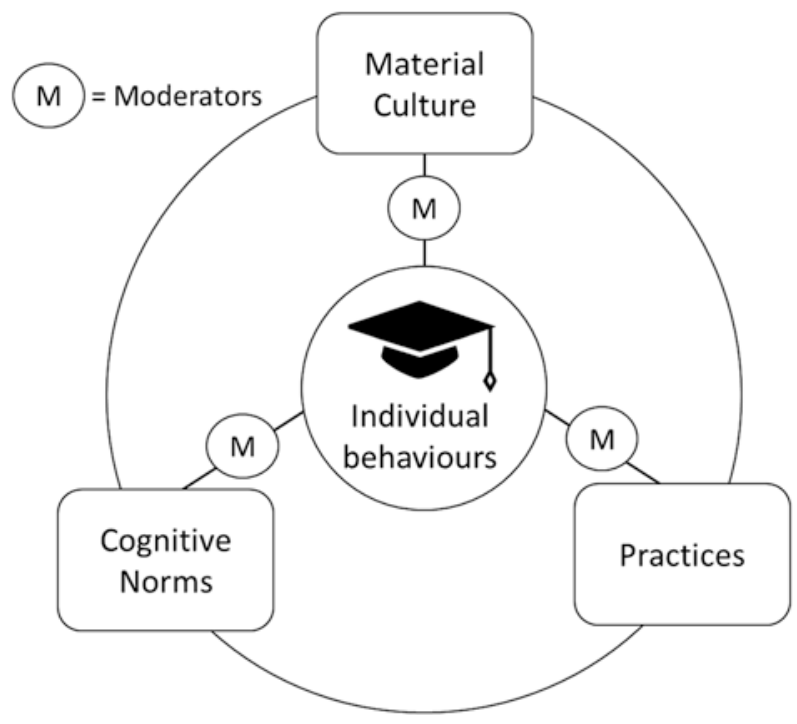

Fig. 13.3 The proposed transport cultures framework. (Source: authors)

manifested itself as generalised anxiety disorder, depressive symptoms and poor sleep quality during the pandemic (Huang \& Zhao, 2020). Furthermore, almost every country closed its borders and/or implemented full or regional lockdown to prevent the spread of the virus (Gössling et al., 2020). Many people were forced to work from home and stop travelling due to lockdowns and border closures. In April 2020, the air transport industry-wide revenue passenger kilometres (RPKs) fell by an unprecedented 94.3 per cent year-on-year (International Aviation Transport Association, 2020). The sudden and dramatic decrease in tourism and air travel caused by COVID-19 is very serious and obvious. However, it is very difficult to determine when and how the pandemic will end since it is usually determined not by medical and public health data, but by socio-political processes (Kolata, 2020).

In response to the COVID-19 pandemic, many conferences were either cancelled or postponed, with some immediately moving online. In order to encourage virtual meetings and conferences, the improvement of technology becomes a crucial issue to increase convenience. Information and communication technology (ICT) is often referred to as a method of 
reducing work-related travel. For instance, virtual communication (via Skype or Zoom meetings) may be able to replace face-to-face contact. Information sharing platforms also plays an important role to smooth the experience of virtual meetings and conferences. By uploading all research materials to a free, open-access online platform, all interested academics can interact with each other and follow the most recent updates in their field (Sarabipour et al., 2020). Online conferences not only provide a more affordable way for academics to connect with each other (Wynes \& Donner, 2018) and generate and share knowledge, they also reduce carbon emissions caused by the transportation of academics and the conference itself (Klöwer et al., 2020; Wynes \& Donner, 2018; Wynes et al., 2019).

For example, the University of California Santa Barbara (UCSB) has dedicated to holding nearly carbon-neutral conferences annually (Environmental Humanities Initiative, 2020). The first nearly carbonneutral conference was held in 2016 (Climate Change: Views from the Humanities) and had a nearly non-existent carbon footprint despite the attendance of 50 speakers from eight countries. In the conferences, all presentations are pre-recorded, with voice-recognition software automatically generating captions which provides an important service for deaf or hard of hearing attendees. Recordings of the presentations are also provided on the conference website, as well as on YouTube and SoundCloud accounts, which makes it easier for participants to listen and watch the presentations in their own time. Additionally, participants can also take part in panel Q\&A sessions for two or three weeks while the conference remains open for interaction with the presenters. The UCSB noticed that, on average, the conferences' Q\&A sessions generated at least three times more discussion than what would normally take place at a traditional Q\&A (with some sessions hosting 10 to 15 times more discussion).

However, there are problems with conferences and meetings moving to an online format following COVID-19. For example, an international team of scientists are writing a global climate science report for the Intergovernmental Panel on Climate Change (IPCC) (Intergovernmental Panel on Climate Change, 2020). The scientists and academics were slated to meet in Ecuador in April for a five-day meeting about how best to reduce 
greenhouse gas emissions and remove carbon dioxide from the atmosphere. Due to the COVID-19 pandemic, the meeting was forced to be held virtually. The biggest challenge the IPCC faced was that the scientists were located in 23 different time zones, and there were only two hours per day that the scientists could meet outside of 12-6 am. The time zone issues prolonged the meeting by an extra two days and, even with the additional time, the scientific goals had to be scaled back. Participation was another serious issue, with a third of the attendees claiming that they were not able to participate fully due to complicated reasons ranging from family and childcare issues to technological issues according to an IPCC survey (Hersher, 2020; Intergovernmental Panel on Climate Change, 2020).

Despite advances in online conferencing technology, many academics complain about the limitations of the technology, such as the quality of the voice or video and firewall settings (Lassen et al., 2006; Wynes \& Donner, 2018). The connection between knowledge of technology and the willingness to use it has become a crucial issue for academics. Also, most academics still prefer building relationships with others through face-to-face meetings. Some researchers suggested changes to meeting and conferences venues. Klöwer et al. (2020) proposed the three-hub model conferences to reduce academic flying miles by holding the conferences simultaneously in three-hub locations, where academics can travel to the nearest hub of the conferences. Sarabipour et al. (2020) suggested replacing national and international meetings with more ground-based travel to regional meetings. This can not only reduce an academic's carbon emissions and costs but also potentially bring benefits to the local community by offering attendees the opportunity to visit local labs, tourist attractions and interacting with the local community.

Based on experiences during the pandemic, this is a good time for academic associations, funding bodies, academic institutions, researchers, conference organisers and virtual-technology providers to rethink how the changes can be made to reduce travel emissions associated with international conferences. By integrating current academic flying practices and experiences gained during COVID-19 with the energy cultures framework, this chapter proposes the transport cultures framework of academic flying in order to suggest pathways in which the necessity of academic travel can be rethought for the future. 


\section{The Transport Cultures Framework of Academic Flying}

The conceptual organising framework developed in this section intends to offer insights into key elements and relationships within the field of academic flying. The transport cultures framework of academic flying is developed by combining the foundational framework and the findings from current academic flying literature and the alternatives implemented during the COVID-19 pandemic. The proposed foundational model (see Fig. 13.3) raises many important questions about changing academic flying practices. It not only focuses on the interactions among material cultures, cognitive norms and practices, but also emphasise the impact of moderators. Based on the energy cultures framework, this chapter categorises all the factors which may influence the motivation behind academic flying into three elements (material culture, practices and cognitive norms) and moderators. From an energy cultures perspective, the material culture, practices and cognitive norms are not only highly interactive, self-reinforcing and self-replicating (Stephenson et al., 2015b), but also shaped or reinforced by the moderators either individually or collectively. It is extremely difficult to break out of the behaviours reinforced by the foundational model's elements (see Fig. 13.3) without a change in at least one of the three elements themselves. However, by changing the moderators, the strength of the relationship between behaviour and element may be modified. This framework can be used to explain how material culture, practices and cognitive norms form academic flying culture and highlight the role of moderators (see Fig. 13.4).

\section{Cognitive Norms}

Cognitive norms reflect academic's attitudes, values, beliefs and understandings about flying-less behaviours. These are the main pressures that force academics to travel and fly frequently. These pressures include university expectations which are directly related to career progression through confirmation (tenure) and promotion. By understanding the 


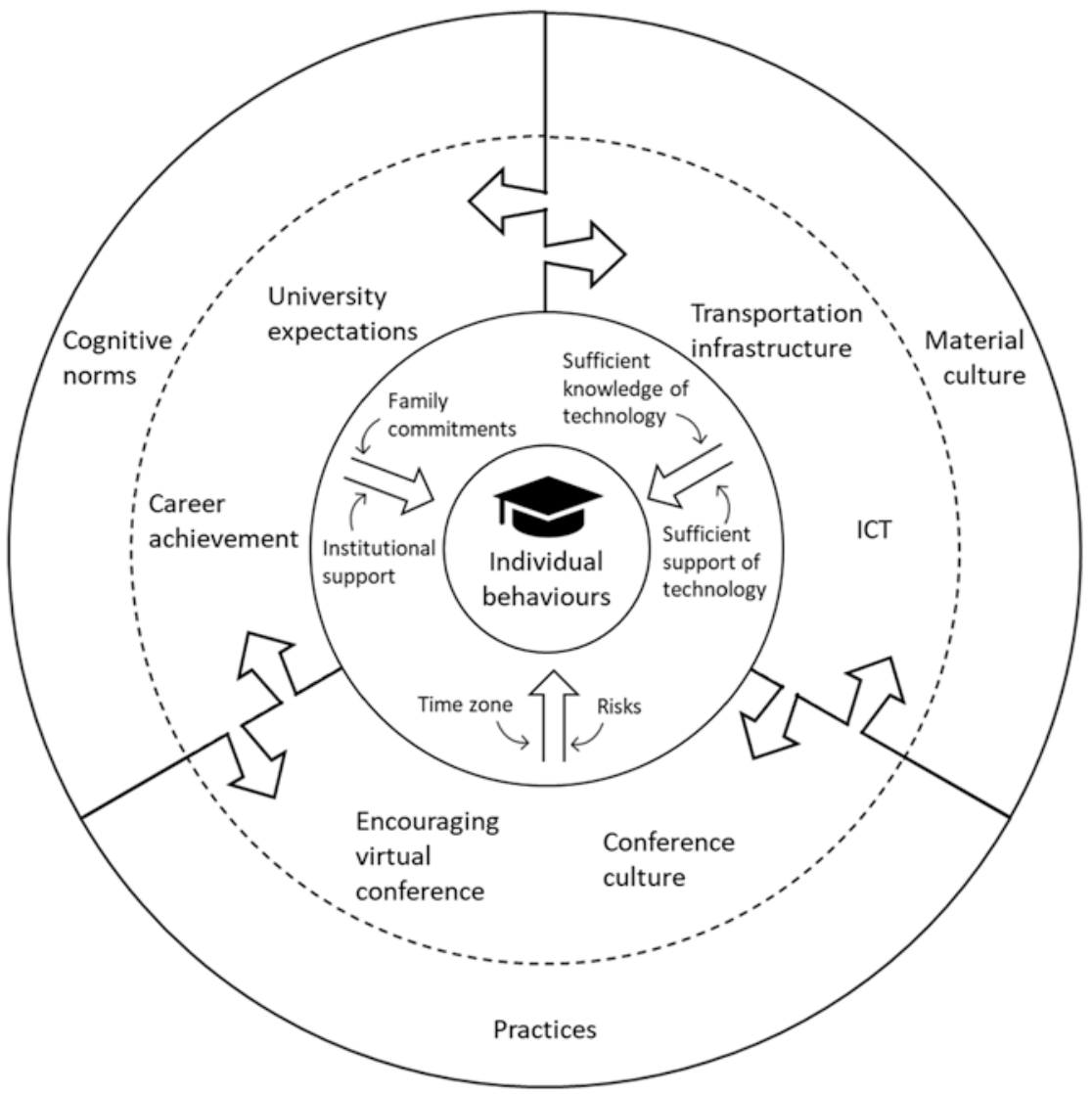

Fig. 13.4 The proposed transport cultures framework of academic flying. (Source: authors)

main pressures that force academics to travel, the related universities and institutions may consider how to change the social atmosphere (e.g. institutional expectations and travel policies) to significantly ease demands on academic staff relating to the necessity for academic flying.

As the key contributors in the institutional internationalisation process, academics seek a balanced, appropriate and effective process which is both in their personal interests and in those of the wider institution (Friesen, 2013). University expectations are usually a reflection of the 
pressure towards internationalisation including international journal publications, collaborations and research grants. Career achievement includes network building, academic performance, career planning and satisfaction. In order to achieve the university's expectations, building and maintaining social networks has become a crucial reason for academic flying, especially for early-career academics. In doing so, their academic performance can be strengthened by collaborative projects and international journal publications, hence, achieving their career plans and work satisfaction.

However, family commitments and institutional support act as moderators between cognitive norms and flying behaviour. While pursuing career progression and fulfilling university expectations, academics spend a lot of time travelling, which reduces engagement with their family. Family commitment has become an important issue which may influence an academic's travel decisions. For example, flying provides a quicker travel option for academics, which also enables decreased time away from family (Glover et al., 2019; Nursey-Bray et al., 2019). As for institutional support, this refers to the support and resources institutions can provide such as the capacity for funding travel, the push for digitalisation and an easy administrative procedure.

\section{Material Cultures}

Material cultures are the available technologies and material products which help academics fly less. Improvements in information and communication technology (ICT) and transportation infrastructure have played an important role in strengthening virtual communication and have reduced the need for air transportation (Wynes \& Donner, 2018).

Information and communication technology (ICT) refers to the capability of institutions to provide a means of stable, high-speed virtual communication technology. With better ICT, it will be easier for academics to attend conferences or build social networks without flying. Transportation infrastructure mainly focuses on the substitution of air transport. The per-person kilometre emission from air transport is much greater than other modes of transportation. Air transport produces 
around $100-250 \mathrm{gCO} / \mathrm{p}-\mathrm{km}$, while rail produces around 40-110 $\mathrm{gCO}_{2} / \mathrm{p}-\mathrm{km}$ and waterborne produces around $20-150 \mathrm{gCO}_{2} /$ p-km (Intergovernmental Panel on Climate Change, 2014). Therefore, carbon emissions may be reduced if academics are able to use rail or water transport to substitute for air transport.

Following the improvement of technology, academics need to update and renew their skills and knowledge to use technology. Sufficient knowledge of technology refers to the moderating influence of whether academics have been provided with sufficient training in ICT, the quality of IT support provided by the institution and the knowledge of using alternative modes of transportation. Sufficient support of technology taps into whether the university provides sufficient support of virtual communication technology to help academics feel comfortable about using technology.

\section{Practices}

Practices reflect the practical aspects of reducing academic flying behaviours. By examining the practices implemented during the period of COVID-19, it is clear that practices can readily and rapidly be changed to reduce academic flying, by encouraging virtual conferences and holding of three-hub model conferences.

Reallocating conference funding, rewarding regional attendance, supporting the reorganisation of conferences based around emissions reduction and inclusivity can be regarded as efficient ways to encourage virtual conferences. For example, carbon budgeting can be an efficient strategy to encourage virtual conferences. Institutions should implement differentiated carbon budgets based on different career stages and other criteria and consider carbon budgeting in grant applications (Klöwer et al., 2020). Conference culture indicates social norms and practices surrounding the use of air travel for work purposes (Whitmarsh et al., 2020). There are many different kinds of options for academics and related institutions to think about. For example, biennial conferences, virtual conferences or three-hub model conferences. Three-hub model conferences take place simultaneously in three-hub locations; academics can travel to 
the nearest hub of the conferences resulting in less carbon emissions (Klöwer et al., 2020).

When important events go purely virtual, time zone differences moderate an academic's motivation and become an issue that needs to be considered since it increases the difficulties for academics to attend meetings or conferences during their work/sociable hours. Because of the spread of COVID-19, many meetings and conferences were forced to be cancelled (e.g. American Academy of Dermatology 2020 Annual Meeting), postponed (e.g. the Twenty-Ninth International Joint Conference on Artificial Intelligence) or held online (e.g. the CAUTHE 2021 conference). According to the experience from COVID-19, it is clear how natural and artificial risks affect people's travelling behaviours. Alongside disease, political issues, wars, terrorism and extreme weather events (Chang, 2016) are also risks that may affect people's travel intentions.

\section{Applying the Framework to the Post-COVID New Normal}

Globally, as of December 2020, there have been more than 66 million confirmed cases and 1.5 million deaths from COVID-19 (World Health Organization, 2020). Baseline forecasts envision a 5.2 per cent contraction in global GDP in 2020, which would be the deepest global recession in decades (The World Bank, 2020). When and how COVID-19 will end is still unclear. However, COVID-19 has shown us how moderators shape elements in the energy cultures framework. In the transport cultures framework of academic flying (see Fig. 13.4), cognitive norms, material culture and practices have a moderated influence on the formation of academic flying behaviours. By changing one or some of the three elements and moderators, the strength of the relationship between behaviour and element may be modified; hence, academic flying behaviour may be changed.

Taking 'material culture' as an example element, based on virtual meeting and conference experiences, most people were satisfied with their experiences, while others noticed the unstable quality due to subpar virtual communication systems or their internet connection (Trust Radius, 
2020). Based on the transport cultures framework of academic flying, solving technological issues would strengthen the intentions of an academic to reduce flying activity and would represent an example where the influence of a moderator can produce elements that produce positive behavioural changes in academic flying. To this end, virtual-technology providers need to develop high-quality and standardised communication systems to optimise virtual communication experiences. Universities should not only provide academics with sufficient IT training and support but also guide investments into new technologies and integrate ICT into everyday operations via a centralised push from administration (Wynes \& Donner, 2018). By strengthening different aspects, the interactions between material culture, moderators and academic's behaviour can be reinforced and produce positive behavioural changes.

The impacts of COVID-19 included the closure of borders and the mandating of social distancing. These impacts incentivised meetings and conferences to go online and showed that the need for academic flying was not as strong as once thought. COVID-19, which functions as a risk moderator, has strengthened the influence of the practices element to reduce academic flying and acted as an example of the influence of moderators on elements. Despite the convenience of virtual conferences and meetings, some academics faced time zone issues. In order to solve this problem, some of the conferences and meetings extended their active hours and days. Moreover, all the presentations were recorded in advance. This allowed participants to watch the presentations in their own time and participate in Q\&A panels at their leisure. While the hurdle of time zones has been overcome, the willingness of reducing academic flying can still be increased. This can serve as a good chance for academics and institutions to rethink the necessity of face-to-face interactions.

\section{Conclusions}

Aviation is the fastest-growing contributor to greenhouse gas emissions (Creutzig et al., 2015). In response to this, many organisations and celebrities have begun to work on reducing the carbon emissions caused by aeromobility (Flight Free UK, 2020; We Stay on the Ground, 2020). 
Academics have been at the forefront of propagandising preventative measures against climate change to society at large. At the same time, they are encouraged to build their collaborative networks, increase publishing frequency, produce high-impact research and maintain visibility through air travel. Because of this perceived hypocrisy, so-called 'climate sceptics' receive validation, while those who warn of the dangers of climate change are continuing, in many cases, to fly without restraint (Higham \& Font, 2020; Wolff, 2019).

The framework presented in this chapter provides insights into factors which form and influence academic flying cultures. The conceptual model builds upon previous research (Stephenson et al., 2010, 2015a; Sweeney et al., 2013) and the experience during the period of COVID-19 (Hersher, 2020; Intergovernmental Panel on Climate Change, 2020; Klöwer et al., 2020). These findings are then applied to the energy cultures framework to explore the individual and institutional pathways to achieving a reduction in academic flying. Future research might build upon this work to evaluate the interactions between the elements of academic flying and the influence of the elements on the motivation to reduce academic flying. By exploring the interplay of the key elements (material culture, practices and cognitive norms), the gap between academic theory and institutional realities will be systematically elaborated and could be undertaken to inform individual and institutional responses to the need to reduce academic air travel emissions. It is also suggested that future research may analyse the perceived value and experience quality of online interaction experiences learnt from the COVID-19 lockdown.

This chapter categorised the necessity, motivation and possible avenues for the reduction of academic flying through the energy cultures framework to explain the systematic academic flying culture. Furthermore, this chapter indicates the online interaction experiences learnt from the COVID-19 lockdown to explore the experiences of working online without flying. This topical issue can help academics to start thinking about replacing physical travel with virtual interactions and encourage academics to engage in critical self-reflection of the cognitive dissonance between personal intentions to reduce air miles and behaviours to the contrary. The transport cultures framework of academic flying presented in this chapter provides a theoretically informed basis for the empirical study of 
academic aeromobility practices, and how they may be actively managed in times of change, to urgently move to more inclusive and climateconscious academic practices.

\section{References}

Air Transport Action Group. (2020). Facts \& Figures. http://www.atag.org Buchs, M. (2019). University sector must tackle air travel emissions. http:// www.theconversation.com/au

Carbon Brief. (2016). Analysis: Aviation could consume a quarter of $1.5 \mathrm{C}$ carbon budget by 2050. http://www.carbonbrief.org

Chang, Y. H. (2016). Airline business and management. Hwa Tai Publishing.

Creutzig, F., Jochem, P., Edelenbosch, O. Y., Mattauch, L., van Vuuren, D. P., McCollum, D., \& Minx, J. (2015). Transport: A roadblock to climate change mitigation? Science, 350(6263), 911-912. https://doi.org/10.1126/science.aac8033

English-Lueck, J. A., Darrah, C. N., \& Saveri, A. (2002). Trusting strangers: Work relationships in four high-tech communities. Information, Communication \& Society, 5(1), 90-108. https://doi.org/10.1080/ 13691180110117677

Environmental Humanities Initiative. (2020). Environmental Humanities Initiative. https://ehc.english.ucsb.edu/

Eriksson, E., Pargman, D., Robèrt, M., \& Laaksolahti, J. (2020, June). On the necessity of flying and of not flying: Exploring how computer scientists reason about academic travel. In Proceedings of the 7 th International Conference on ICT for Sustainability (pp. 18-26). https://doi.org/10.1145/ 3401335.3401582

Flight Free UK. (2020). http://www.flightfree.co.uk

Friesen, R. (2013). Faculty member engagement in Canadian university internationalization: A consideration of understanding, motivations and rationales. Journal of Studies in International Education, 17(3), 209-227. https:// doi.org/10.1177/1028315312451132

Glover, A., Strengers, Y., \& Lewis, T. (2017). The unsustainability of academic aeromobility in Australian universities. Sustainability: Science, Practice and Policy, 13(1), 1-12. https://doi.org/10.1080/15487733.2017.1388620 
Glover, A., Lewis, T., \& Strengers, Y. (2019). Overcoming remoteness: The necessity of air travel in Australian universities. Australian Geographer, 50(4), 453-471. https://doi.org/10.1080/00049182.2019.1682319

Gössling, S., Scott, D., \& Hall, C. M. (2020). Pandemics, tourism and global change: A rapid assessment of COVID-19. Journal of Sustainable Tourism, 1-20. https://doi.org/10.1080/09669582.2020.1758708

Grant, C. (2018). Academic flying, climate change, and ethnomusicology: Personal reflections on a professional problem. Ethnomusicology Forum, 27(2), 123-135. https://doi.org/10.1080/17411912.2018.1503063

Greenbank, P. (2006). The academic's role: The need for a re-evaluation? Teaching in Higher Education, 11(1), 107-112. https://doi.org/10.1080/ 13562510500400248

Growe, A. (2019). Developing trust in face-to-face interaction of knowledgeintensive business services (KIBS). Regional Studies, 53(5), 720-730. https:// doi.org/10.1080/00343404.2018.1473567

Hair, J. F., Jr., Hult, G. T. M., Ringle, C., \& Sarstedt, M. (2016). A primer on partial least squares structural equation modeling (PLS-SEM). Sage Publications. Hersher, R. (2020). Everyone loves the chat box: How climate science moved online. National Public Radio. http://www.npr.org

Higham, J., \& Font, X. (2020). Decarbonising academia: Confronting our climate hypocrisy. Journal of Sustainable Tourism, 28(1), 1-9. https://doi.org/1 $0.1080 / 09669582.2019 .1695132$

Higham, J., Hopkins, D., \& Orchiston, C. (2019). The work-sociology of academic aeromobility at remote institutions. Mobilities, 14(5), 612-631. https://doi.org/10.1080/17450101.2019.1589727

Hopkins, D., \& Stephenson, J. (2014). Generation Y Mobilities through the lens of energy cultures: A preliminary exploration. Journal of Transport Geography, 38, 88-91.

Hopkins, D., \& Stephenson, J. (2016). The replication and reduction of automobility: Findings from Aotearoa New Zealand. Journal of Transport Geography, 56, 92-101. https://doi.org/10.1016/j.jtrangeo.2016.09.005

Hopkins, D., Higham, J., Tapp, S., \& Duncan, T. (2016). Academic mobility in the Anthropocene era: A comparative study of university policy at three New Zealand institutions. Journal of Sustainable Tourism, 24(3), 376-397. https:// doi.org/10.1080/09669582.2015.1071383

Huang, Y., \& Zhao, N. (2020). Generalized anxiety disorder, depressive symptoms and sleep quality during COVID-19 outbreak in China: A web-based 
cross-sectional survey. Psychiatry research, 112954. https://doi.org/10.1016/j. psychres.2020.112954

Intergovernmental Panel on Climate Change. (2014). Mitigation of climate change. Contribution of Working Group III to the Fifth Assessment Report of the Intergovernmental Panel on Climate Change, 1454.

Intergovernmental Panel on Climate Change. (2020). IPCC develops strategic response to impact of COVID-19 on work programme. http://www. ipcc.ch/news

International Aviation Transport Association. (2020). Air passenger market analysis. http://www.iata.org/economics-terms

International Civil Aviation Organization. (2017). 2016 environmental report. http://www.icao.int

International Civil Aviation Organization. (2020). Carbon Offsetting and Reduction Scheme for International Aviation (CORSIA). https://www.icao. int/environmental-protection/CORSIA/Pages/default.aspx

International Energy Agency. (2020). Tracking Transport 2020. http://www.iea. org/reports/tracking-transport-2020

Klaniecki, K., Duse, I. A., Lutz, L. M., Leventon, J., \& Abson, D. J. (2020). Applying the energy cultures framework to understand energy systems in the context of rural sustainability transformation. Energy Policy, 137, 111092. https://doi.org/10.1016/j.enpol.2019.111092

Klöwer, M., Hopkins, D., Allen, M., \& Higham, J. (2020). An analysis of ways to decarbonize conference travel after COVID-19. Nature, 583, 356-359. https://doi.org/10.1038/d41586-020-02057-2

Knight, J. (2011). Five myths about internationalization. International Higher Education, 62. https://doi.org/10.6017/ihe.2011.62.8532

Kolata, G. (2020). How pandemics end. http://www.nytimes.com

Lassen, C., Laugen, B. T., \& Næss, P. (2006). Virtual mobility and organizational reality - A note on the mobility needs in knowledge organisations. Transportation Research Part D: Transport and Environment, 11(6), 459-463. https://doi.org/10.1016/j.trd.2006.09.001

McKague, F., Lawson, R., Scott, M., \& Wooliscroft, B. (2016). Understanding the energy consumption choices and coping mechanisms of fuel poor households in New Zealand. New Zealand Sociology, 31(1), 106-126.

Moore, R. H., Thornhill, K. L., Weinzierl, B., et al. (2017). Biofuel blending reduces particle emissions from aircraft engines at cruise conditions. Nature, 543(7645), 411-415. https://doi.org/10.1038/nature21420

New Zealand Education Act, 80 C.F.R. (1989). 
Nicomedes, C., \& Avila, R. (2020). An analysis on the panic during COVID-19 pandemic through an online form. Journal of Affective Disorders, 276, 14-22. https://doi.org/10.1016/j.jad.2020.06.046

Nursey-Bray, M., Palmer, R., Meyer-Mclean, B., Wanner, T., \& Birzer, C. (2019). The fear of not flying: Achieving sustainable academic plane travel in higher education based on insights from South Australia. Sustainability, 11(9), 2694. https://doi.org/10.3390/su11092694

Overton, J. (2019). Fact sheet: The growth in greenhouse gas emissions from commercial aviation. http://www.eesi.org

Rumbley, L., Altbach, P., \& Reisberg, L. (2012). Internationalization within the higher education context. In D. K. D. H. de Wit \& J. D. Heyl (Eds.), The SAGE handbook of international higher education (pp. 3-26). SAGE Publications, Inc. https://doi.org/10.4135/9781452218397.n1

Sarabipour, S., Schwessinger, B., Mumoki, F. N., Mwakilili, A. D., Khan, A., Debat, H. J., et al. (2020). Evaluating features of scientific conferences: A call for improvements. BioRxiv. https://doi.org/10.1101/2020.04.02.022079

Sarrica, M., Brondi, S., Cottone, P., \& Mazzara, B. M. (2016). One, no one, one hundred thousand energy transitions in Europe: The quest for a cultural approach. Energy Research \& Social Science, 13, 1-14. https://doi. org/10.1016/j.erss.2015.12.019

Stephenson, J., Barton, B., Carrington, G., Gnoth, D., Lawson, R., \& Thorsnes, P. (2010). Energy cultures: A framework for understanding energy behaviours. Energy Policy, 38(10), 6120-6129. https://doi.org/10.1016/j. enpol.2010.05.069

Stephenson, J., Lawson, R., Carrington, G., Barton, B., \& Thorsnes, P. (2011, November). Energy cultures - A framework for interdisciplinary research. In World Renewable Energy Congress-Sweden, 8-13 May 2011, Linköping, Sweden (No. 057, pp. 1023-1030). Linköping University Electronic Press. https:// doi.org/10.3384/ecp110571023

Stephenson, J., Barton, B., Carrington, G., Doering, A., Ford, R., Hopkins, D., et al. (2015a). The energy cultures framework: Exploring the role of norms, practices and material culture in shaping energy behaviour in New Zealand. Energy Research \& Social Science, 7, 117-123. https://doi.org/10.1016/j. erss.2015.03.005

Stephenson, J., Hopkins, D., \& Doering, A. (2015b). Conceptualizing transport transitions: Energy Cultures as an organizing framework. Wiley Interdisciplinary Reviews: Energy and Environment, 4(4), 354-364. https:// doi.org/10.1016/j.enpol.2010.05.069 
Storme, T., Beaverstock, J. V., Derrudder, B., Faulconbridge, J. R., \& Witlox, F. (2013). How to cope with mobility expectations in academia: Individual travel strategies of tenured academics at Ghent University, Flanders. Research in Transportation Business \& Management, 9, 12-20. https://doi.org/10.1016/j.rtbm.2013.05.004

Sweeney, J. C., Kresling, J., Webb, D., Soutar, G. N., \& Mazzarol, T. (2013). Energy saving behaviours: Development of a practice-based model. Energy Policy, 61, 371-381. https://doi.org/10.1016/j.enpol.2013.06.121

The World Bank. (2020). Global economic prospects. https://www.worldbank. org/en/publication/global-economic-prospects

Times Higher Education. (2020). The world university rankings 2020:

Methodology. http://www.timeshighereducation.com

Trust Radius. (2020). Zoom reviews. http://www.trustradius.com

Urry, J. (2012). Social networks, mobile lives and social inequalities. Journal of Transport Geography, 21, 24-30. https://doi.org/10.1016/j.jtrangeo.2011.10.003 Walton, S., Zhang, A., \& O'Kane, C. (2020). Energy eco-innovations for sustainable development: Exploring organizational strategic capabilities through an energy cultures framework. Business Strategy and the Environment, 29(3), 812-826. https://doi.org/10.1002/bse.2399

We Stay on the Ground. (2020). http://www.westayontheground.blogspot.com Whitmarsh, L., Capstick, S., Moore, I., Köhler, J., \& Le Quéré, C. (2020). Use of aviation by climate change researchers: Structural influences, personal attitudes, and information provision. Global Environmental Change, 65, 102184. https://doi.org/10.1016/j.gloenvcha.2020.102184

de Wit, H. (2018). Internationalisation of HE - Successes and failures. http:// www.universityworldnews.com

Wolff, J. (2019). What hypocrisy, I think guiltily, as I jet off to academic conferences far and wide. http://www.theguardian.com

World Health Organization. (2020). WHO coronavirus disease (COVID-19) dashboard. https://www.covid19.who.int/

Wynes, S., \& Donner, S. D. (2018). Addressing greenhouse gas emissions from business-related air travel at public institutions: A case study of the University of British Columbia. Pacific Institute for Climate Solutions.

Wynes, S., Donner, S. D., Tannason, S., \& Nabors, N. (2019). Academic air travel has a limited influence on professional success. Journal of Cleaner Production, 226, 959-967. https://doi.org/10.1016/j.jclepro.2019.04.109 
Open Access This chapter is licensed under the terms of the Creative Commons Attribution 4.0 International License (http://creativecommons.org/licenses/ by/4.0/), which permits use, sharing, adaptation, distribution and reproduction in any medium or format, as long as you give appropriate credit to the original author(s) and the source, provide a link to the Creative Commons licence and indicate if changes were made.

The images or other third party material in this chapter are included in the chapter's Creative Commons licence, unless indicated otherwise in a credit line to the material. If material is not included in the chapter's Creative Commons licence and your intended use is not permitted by statutory regulation or exceeds the permitted use, you will need to obtain permission directly from the copyright holder.

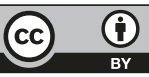

